\title{
Article
}

\section{Ultimate attainment in the use of collocations among heritage speakers of Turkish in Germany and Turkish-German returnees}

Treffers-Daller, Jeanine, Daller, Michael, Furman, Reyhan and Rothman, Jason

Available at http://clok.uclan.ac.uk/12910/

Treffers-Daller, Jeanine, Daller, Michael, Furman, Reyhan ORCID: 0000-00016034-3820 and Rothman, Jason (2016) Ultimate attainment in the use of collocations among heritage speakers of Turkish in Germany and TurkishGerman returnees. Bilingualism: Language and Cognition, 19 (3). pp. 504-519. ISSN 1366-7289

It is advisable to refer to the publisher's version if you intend to cite from the work. http://dx.doi.org/10.1017/S1366728915000139

For more information about UCLan's research in this area go to http://www.uclan.ac.uk/researchgroups/ and search for < name of research Group>.

For information about Research generally at UCLan please go to http://www.uclan.ac.uk/research/

All outputs in CLoK are protected by Intellectual Property Rights law, including Copyright law. Copyright, IPR and Moral Rights for the works on this site are retained by the individual authors and/or other copyright owners. Terms and conditions for use of this material are defined in the policies page. 


\begin{abstract}
In this paper we show that heritage speakers and returnees are fundamentally different from the majority of adult second language learners with respect to their use of collocations (Laufer \& Waldman, 2011). We compare the use of lexical collocations involving yap- "do" and et- "do" among heritage speakers of Turkish in Germany $(n=45)$ with those found among Turkish returnees $(n=65)$ and Turkish monolinguals $(n=69)$. Language use by returnees is an understudied resource although this group can provide crucial insights into the specific language ability of heritage speakers. Results show that returnees who had been back for one year avoid collocations with yap- and use some hypercorrect forms in et-, whilst returnees who had been back for seven years upon recording produce collocations that are quantitatively and qualitatively similar to those of monolingual speakers of Turkish. We discuss implications for theories of ultimate attainment and incomplete acquisition in heritage speakers.
\end{abstract}




\section{Introduction}

This paper contributes to the debate around the nature of heritage languages by comparing the use of collocations among heritage speakers (HSs) to that of returnees, that is HSs who have returned to their parents' country of origin. So far, not many researchers have analyzed the language used by returnees (but see Flores, 2010; Treffers-Daller, Van Hout \& Özsoy, 2007; Daller, Treffers-Daller \& Furman, 2011), although this group of bilinguals is very relevant to gain further insight into what aspects of grammatical or lexical knowledge are vulnerable among speakers of heritage languages. HSs are a specific category of bilinguals in the sense that they learned language $\mathrm{X}$ - the 'heritage language' - as an L1 in childhood, but became more proficient or dominant in another language later in childhood (Benmamoun, Montrul \& Polinsky, 2013). While researchers adopt different definitions of HSs, most agree that an important characteristic of HSs is that they are not primarily educated in their heritage language (cf. Pascual y Cabo \& Rothman, 2012). The input is often restricted to oral input in family situations, which sets this group apart from bilingual children who grow up in a situation where there is extensive support for the development of both languages in oral and written form.

According to Montrul and Bowles (2009), by the time HSs reach adolescence and early adulthood, they are different from monolinguals in some ways that resemble adult L2 acquirers. The authors claim that they have failed to acquire the language completely, partly through attrition of properties once known but which were subsequently lost and partly because some properties were never acquired in the first place. Montrul and Bowles specify that only particular properties are affected by incomplete acquisition in HSs. An important question remains as to which features are at risk of being represented differently in heritage grammars and what language-internal and language-external factors conspire to cause this. Answers to this important question would not only bring us towards explanatory adequacy in 
the study of heritage languages, but would provide some level of predictive and ecological validity in this burgeoning field of inquiry. Montrul and Bowles $(2009$, p. 381) note that "incomplete acquisition is like "going back to basics": it leads to simplification of the grammar by letting go of some of the most marked, language specific, non-core options, while retaining the core, universal, functional structure".

The current paper focuses on a lexical domain that L2 learners find very difficult to acquire in particular after the age of twelve, namely fixed expressions that are conventional in the target language speech community. Pawley and Syder (1983, p. 194) coined the term "native-like selection" ${ }^{\mathrm{i}}$ " for the ability to "know which of the well-formed sentences are native-like - a way of distinguishing those usages that are normal or unmarked from those that are unnatural or highly marked". They assume that native speakers of a language have somehow stored a wide range of lexicalized sentence stems, i.e. "a unit of clause length ${ }^{\mathrm{ii}}$ or longer whose grammatical form and lexical content is wholly or largely fixed" (Pawley \& Syder, 1983, p. 191). Thus, they know that make an effort is a common collocation but do an effort is not. According to Ellis (2002), native speakers build up knowledge about the probabilities with which words co-occur through a process of associative learning. The SLA literature shows that second language learners (L2 learners) find it very difficult to acquire such collocational knowledge. Foster (2009a), for example, shows that even at very advanced stages of acquisition, L2 learners of English underuse collocations involving delexicalized verbs, which are also known as light verbs (Jespersen, 1954), such as have a drink or have a swim, although these are very common among monolingual native speakers. Similar findings regarding the difficulties experienced by L2 learners in producing collocations, including those involving delexicalized verbs such as do, have or make, can be found in many other studies. This appears to be a universal problem for L2-learners from a wide variety of L1 backgrounds, including those with advanced levels of language proficiency (see Laufer \& 
Waldman, 2011 for an overview). Exceptions may be learners who use repetition and memorisation of entire texts as their key language learning strategy, such as those described in Ding (2007). The onset of the L2 acquisition process is an important predictor variable for students' ability to process formulaic language. Foster shows that L2 learners who started learning English after the age of twelve do not perform within the monolingual native speaker range in recognising that expressions such as The ball came up by floating are somehow odd. Thus, she assumes there is an age effect on ultimate attainment in SLA, in that late learners (i.e. in their study those who started after the age of twelve) are no longer able to distinguish between word combinations that are conventional among monolingual native speakers of the target language and those that are not because of diminished pattern recognition and memory functions (Foster, 2009b). It is important to note that these are not language-specific abilities, but generic cognitive functions which tend to decrease with age.

However, there could also be other causes for L2 learners' problems with collocations. According to Wray (2009), native speakers learn idiomatic expressions by observing and imitating the group with whom they most strongly identify. It is possible that L2 learners do not wish to identify that strongly with the target culture and language and that their lack of success with idiomatic expressions results from them making less of an effort to observe and imitate target language speakers. Sociolinguistic explanations could therefore provide additional reasons for the apparent lack of success of L2 learners in this domain, which will be explored further in the discussion section of this paper.

In a previous paper (Rothman \& Treffers-Daller, 2014) we have made the point that monolinguals are not the only speakers that should be considered as native speakers. Heritage speakers are native speakers of their languages too, but at the same time they have a specific competence that may be characterized by significant differences to the monolingual baseline. The question then remains at which linguistic levels bilinguals are different from 
monolinguals, and to what extent collocational patterns found among bilinguals differ from those found among monolinguals. This paper aims to contribute to shedding new light on this issue by looking at a domain that has not been studied among HSs so far, namely their ability to use collocations in the same way as monolinguals living in the country of origin. Studying collocations is very important if one wants to know to what extent HSs are similar to monolingual native speakers of their language or to L2 learners. In particular the study of returnees can show new light on the specific language profiles of HSs. In adolescence some HSs return to their parents' country of origin, and at that point they need to acquire new collocations because some of those being used among HSs communities differ from those used in their new environment (see section 2 for details). If HSs resemble L2 learners, as Montrul and Bowles (2009) argue, learning new collocations should be very difficult for this group, because this has been shown to be virtually impossible for L2 learners (Foster, 2009). However, if childhood exposure advantages HSs for later modification of grammars towards a new input variety, namely the monolingual variety upon returning to Turkey, then they should show distinct patterns of acquisition of collocations than what Foster has shown for L2 acquisition in adulthood.

The current study focuses on Turkish-German HSs and returnees because there are large groups of Turkish-German bilinguals in Germany as well as Turkey due to the extensive migration movement between both countries (Daller \& Treffers-Daller, 2014). The migration patterns of Turkish-German bilinguals make this group unique: we can compare them not only with monolinguals of each language, as is done in most studies, but we can also study differences between adult bilinguals with different migration histories, namely the ones who were born and grew up in Germany and have stayed there all their lives (the heritage speakers) and those who went back to Turkey in adolescence (the returnees). These two groups differ from each other with respect to the amount of input they received in 
Turkish from early adolescence onwards, and with respect to the purposes for which they used Turkish in daily life. The HSs continued using Turkish in informal contexts only, while the returnees entered the Turkish school system and subsequently continued studying at a Turkish university. The returnees were thus exposed to larger amounts of Turkish input from early adolescence onwards. However, this fact also means that unlike the HSs in Germany, they have received formal education in the language which provides them more guaranteed access to standard Turkish as well. Thus, they differ not only in quantity of exposure to Turkish starting in late adolescence but also with respect to different linguistic qualities of the input, which according to Rothman (2007) and Pires and Rothman (2009) might be responsible for some differences in heritage grammars that others label as so-called “incomplete properties". Comparing the returnees' knowledge of Turkish with that of bilinguals who remained in Germany gives us a unique window regarding ultimate attainment in heritage languages spoken in immigration contexts, and the impact of input quantity and quality on ultimate attainment in those contexts in particular. To our knowledge, there are no other studies that look in any detail at conventional patterns and the implications for theories of ultimate attainment of the language profiles of returnees, and only very few studies that compare HSs with returnees at all (see Flores, 2010).

In this context it is important to note that Rothman (2007) and Pires and Rothman (2009) distinguish between two types of competence divergences among HSs. The first type is true incomplete acquisition, where properties that are clearly present in the input are seemingly represented differently in HS grammars, that is, the heritage speakers had access to input needed to acquire a given property. The second type is missing-input competence divergence, whereby the input itself provided to heritage speakers is not sufficient for the acquisition of a given property. In such a case, HSs have no recourse but to converge on different grammars from monolingual peers. Rothman and Pires (2009) hypothesize two 
scenarios under which this obtains: (a) when L1 attrition in previous generations alters input (see Sorace, 2004; Pascual y Cabo \& Rothman, 2012) and (b) properties that have undergone diachronic change in colloquial dialects, yet remain mostly in the standard variety of the language accessed primarily via education (e.g. pied-piping as opposed to preposition stranding in English or inflected infinitives in Brazilian Portuguese). A comparison of the performance patterns to be discussed below will allow us to explore which hypothesis is the most appropriate for the current data.

Given that the domain of inquiry involves lexis, it makes the most sense to adopt a usage-based approach (e.g. Ellis, 2002; MacWhinney, 2005; O’Grady, 2013). Such an approach would probably claim that it is the different amount of Turkish input to HSs and returnees which explains the differences in their language profiles. It is only when input reaches levels comparable to those typically present in L1 acquisition of Turkish in Turkey, that learners develop those aspects of grammar that have so far eluded them. The returnee group should be able to modify their Turkish (grammar as well as vocabulary) after return to Turkey, despite the fact that they are well into puberty at the time of arrival, and should not be significantly different from Turkish monolingual speakers after a number of years of residence in Turkey.

The situation of Turkish-German returnees is rather different from that of the majority of L2 learners in this respect. As Brach (2012), Sackmann, Schultz, Prümm, and Peters (2005) and Schneider (2009) point out, there is a certain stigma attached to being a returnee from Germany: they are referred to as Almancılar, the name used in Turkey for Turks living in Germany, which has negative connotations. Turkish-German returnees find themselves under considerable social pressure to integrate into Turkish culture and learn a new variety of Turkish as spoken in Turkey (Fritsche, 1996). As shown in Daller $(1999,2005)$ many returnees do not feel confident speaking Turkish upon returning, and some express concerns 
about their ability to use Turkish even seven years after returning. The pressure to conform makes the situation of returnees very different from that of typical L2 learners, and as a result, the outcome of their (re-)learning of their heritage language is different too.

Comparing HSs and returnees is particularly relevant if we can assume that at the moment of arrival in Turkey, returnees had the kind of knowledge of these collocations that is displayed by HSs at the age of 13-15. It is clear that this can only be assumed because we do not have information about the state of knowledge of the returnees at the moment of (r)emigration to Turkey. The only way to do that would be to follow a group longitudinally, but such data are only available for a very small group who were followed for a short period of time after returning (see Treffers-Daller et al., 2007). A similar cross-sectional comparison was made by Polinsky (2011), who studied knowledge of relativization among child and adult HSs of Russian, with the aim to tease apart the effects of incomplete acquisition and attrition among adult HSs. We assume that our HSs and returnee groups are indeed comparable in that they belonged to the same group of HSs until the point at which the returnees moved to Turkey (see Figure 1). In order to corroborate this assumption we have carefully analysed the questionnaire data which were obtained from each group (see Methods for further details).

[Insert Figure 1 about here]

While the patterns used by HSs can give us information about Turkish usage among returnees before the point of return, patterns used by monolingual speakers of Turkish in Turkey will form the point of reference for investigating to what extent returnees are successful in acquiring monolingual patterns that are common in the variety they encounter 
upon return to Turkey. If returnees who had been back for many years at the time of recording are not significantly different from monolinguals in their use of collocations, we conclude that they must have acquired such patterns after arrival in Turkey, and that the returnees are capable of replacing patterns that were common in the variety of Turkish they spoke in Germany with new patterns that belong to the variety of Turkish they are exposed to after arrival. We will argue that this scenario, should it be shown, can be used as an indirect means to differentiate between true incomplete acquisition and missing input delimited differences that characterise heritage speaker grammars more general.

The paper is structured as follows. First we sketch some characteristics of Turkish as spoken in Europe (mainly the Netherlands and Germany) in relation to the use of conventional patterns, specifically with respect to light verb constructions involving yap- and et- (section 2). In section 3 the methods used in this project are presented, and in section 4 the focus is on the results. We conclude with a general discussion of the implications of our findings for theories of ultimate attainment in HSs (section 5).

\section{Conventional patterns in Turkish as spoken in Europe: the case of yap- and et-} It has been known since at least the 1980s that Turkish as spoken in Europe by immigrant children from Turkey differs from Turkish as spoken in Turkey with respect to a range of morphosyntactic and lexical features (Boeschoten, 1990; Fritsche, 1982; Pfaff, 1991; Rehbein, 1987; Schaufeli, 1991; Verhoeven \& Boeschoten, 1986). Recently, the focus has shifted from the analysis of morphosyntactic features to the use of fixed combinations of words, in line with recent developments in SLA where such combinations, often called formulaic sequences (Wray, 2002) or multiword items, are receiving a lot of attention. As explained in the introduction to this chapter, learning to express oneself in conventional ways in a second language by choosing combinations of words that are the unmarked way of 
talking about things is very difficult for L2 learners, even at advanced levels (e.g. Durrant \& Schmitt, 2010; Foster, 2009a, b). Less is known about the ability of HSs to acquire these aspects of everyday language use, how HSs' knowledge of a second language affects their use of multiword expressions, and to what extent returnees are able to adapt to the use of a different range of expressions after arrival in Turkey.

One phenomenon that has been noticed across diaspora varieties of Turkish in Germany, the Netherlands, Norway and France is the prolific use of yap- "to do" in a range of functions which are different from those used in Turkish as spoken in Turkey. In a recent paper Doğruöz and Backus (2009) distinguish three such uses, two of which will be discussed here $\mathrm{iii}^{\mathrm{ii}}$. The first of these is the use of noun-verb collocations [N-yap] such as Fransizca yapin (1), where Turkish-Dutch bilinguals use the verb yap- instead of more specific lexical verbs such as oku- "read" with yap- in (2) . ${ }^{\text {iv }}$ Fransizca oku- "to read French" is the variant used in Turkish as spoken in Turkey, when talking about choices of school subjects.

(1) Ben okul-da bir sene Fransizca yap-t-ım (NL-Turkish)

I school-LOC one year French make-PAST-1SG.

"I studied French for a year at school."

(2) Ben okul-da bir sene Fransizca oku-du-m (TR-Turkish)

I school-LOC one year French read-PAST-1SG

"I studied French for one year at school."

Similar occurrences where yap- replaces a more specific Turkish word were also found by Pfaff (2000), who notes that fotograf yap- is often used in examples such as (3) instead of the more specific fotoğraf çek- which is common in Turkish as spoken in Turkey. Pfaff notes that this use could have been influenced by German, where saying Photos machen "to make 
pictures" is very usual, but she also observes that not all such occurrences can be explained on the basis of transfer from German, as the same child also produces Benzin yapiyo "makes/does fuel" in (4), although Benzin machen/tun is not a common expression in Standard German for filling up the fuel tank.

(3) Fotoğraf yap-1yor-lar (Pfaff, 2000, p. 369)

Picture make-PROG-PL (Serkan, 5;09)

"They are taking pictures."

(4) Benzin yap-1yo (Serkan, 5;04) (Pfaff, 2000, p. 369)

Fuel make-PROG- $\varnothing$

"He is filling (his car) with gasoline."

Thus, a new set of noun-verb collocations [N-yap] is created which are innovations by comparison with Turkish as spoken in Turkey (see Boeschoten, 1998; Johansson, 1998 for more details).

The patterns found are an extension of constructions which exist in many languages, including English, and which are often referred to as light verb constructions, a term coined by Jespersen (1954). Light verbs are verbs which cannot stand on their own in a sentence but can be combined with another verb or a nominal (Göksel \& Kerslake, 2005; Kornfilt, 1997; Uçar, 2010). The construction is called "light" because the verb does not make an independent contribution to the meaning of the construction. Examples of regular and light verb constructions in English are given in (5a), where the full lexical verb offer is used, and 
(5b) where this verb is replaced with the light verb construction make an offer, and (6a) and

(6b) which illustrate the use of ver- "to give" as a free verb and a light verb respectively.

(5a) John offered a drink to Nancy

(5b) John made an offer of a drink to Nancy (Özbek, 2010, p. 3)

(6a) Ali Ahmet-e bir hediye ver-di

Ali Ahmet-DAT a present give-PAST

“Ali gave Ahmet a present.” (Uçar, 2010)

(6b) Ali Ahmet-e destek ver-di

Ali Ahmet-DAT support give-PAST

“Ali supported Ahmet.” (Uçar, 2010)

Many researchers note that it is possible to use et- instead of yap- in these constructions in diaspora varieties, but yap- is the more popular choice (Türker, 2000). Pfaff (2000, p. 369) also notes that there is a preference for yap- among Turkish-German children in Berlin, as can be seen in the utterances of İlknur who uses et- in earlier recordings but yap- in later ones, "thus increasingly confirming to the diaspora variety of her peers", as in (7a) and (7b).

(7a) Kavga ed-iyo (İlknur 4;04)

Fight do-PROG- $\varnothing$

"He is fighting."

(7b) Kavga yap-lyor-lar (İlknur 6;04) 
Fight do-PROG-PL

"They are fighting."

The second category of yap-constructions forms a further extension of this pattern. Pfaff (1990) was probably the first to notice the use of yap- to incorporate German verbs into Turkish as spoken in Germany, while Backus (1996) and Türker (2000) note the same uses of yap- in Dutch Turkish and Norwegian Turkish respectively. The Turkish verb yap- carries the inflection whilst the German verb is in the infinitive, as in (8), where gratulieren "to congratulate" is an infinitive form, but yapıyo is inflected for tense/aspect, person and number ${ }^{\mathrm{v}}$. Turkish verbs are not used in combination with yap-.

(8) Bei laufen, bei Lau ähm- koşunda on Runde’yi yapa/ When running, when run- erm when running ten round-ACC do yap-an-lar-a gratulieren yapıyo do-REL-PL-DAT congratulate do-PROG- $\varnothing$. "When running, erm when running, s/he [=the teacher] congratulates those who do ten laps." (Pfaff, 2013)

Muysken (2000) provides a detailed typology of bilingual complex verbs across a range of language pairs and bilingual communities, showing that these consist of a helping verb meaning "make" or "do" from the matrix or host language, and a lexical verb from the embedded language (Muysken, 2000, p. 184). In the cases under discussion here, Turkish would be the matrix or host language, and the embedded language would be a language 
spoken in the societies to which the speakers of Turkish immigrated (Dutch, German or Norwegian in the examples under discussion here).

Backus (1996) in his study of different generations of Dutch Turks notes that the first generations mainly use yap- with nouns from the embedded language, as in on Runde-yi yap"do ten rounds" whereas later generations increasingly use yap- in mixed verbal compounds, such as gratulieren yap- "to congratulate", which is also common among German Turks.

Given the fact that the noun verb collocations [N-yap] and [N-et] occur in Turkish as spoken in Turkey too, it is to be expected that the first generation of Turkish immigrants uses this strategy, whilst later generations expand on the available patterns to create bilingual complex verbs. In principle, both et- and yap- can be used for these, as shown in (9), although many researchers observe that in diaspora varieties yap- frequently replaces et- in these constructions (Türker, 1993; Muysken, 2000).

$\begin{array}{lllll}\text { (9) Ben } & \text { feiern } & \text { yap-ml-yca-m } & \text { ki [pause] } & \text { ama feiern } \\ \text { I } & \text { celebrate } & \text { do-NEG-FUT-1SG } & \text { INT } & \text { but celebrate }\end{array}$

et-mi-yor-um ki

do-NEG-PROG-1SG INT

"I will not celebrate my birthday but I do not celebrate." (Kallmeyer \& Keim, 2003, p.

To summarize, the yap- patterns form an extension of patterns which are available in Turkish as spoken in Turkey, although the constructions are also at least in part explainable as the result of language contact, which has probably helped to propagate the new forms in the bilingual speech community. The noun-verb collocations are probably closest related to 
the patterns found in Turkish as spoken in Turkey, whereas the bilingual complex verbs are a step further away from this variety. Both the noun-verb collocations and the bilingual complex verbs are preferably constructed with yap- rather than et-. While the use of yap- is thus clearly the unmarked choice in the diaspora varieties and et- is the unmarked one in Turkey, the differences between the diaspora varieties and the one spoken in Turkey are not absolute: the differences are of a probabilistic nature and the choices made are subject to sociolinguistic factors. One such factor is the generation to which the speaker belongs, and another is social pressure from peers. Thus, Backus (1996) shows that second generation speakers use more bilingual complex verbs than the first or the intermediate generation. In a similar vein, Pfaff (2000) shows there is a tendency, on the part of small children, to adopt the choices of the majority and to increasingly use yap- instead of et- to form noun-verb collocations.

The current paper contributes to the ongoing discussion about these collocations and complex verbs by investigating how Turkish HSs in Germany and Turkish returnees differ from each other in their use of these, and how length of residence in Turkey affects the frequency with which they are used. We expected younger and older heritage speaker groups to use a) more [N-yap] and fewer [N-et] collocations and b) more bilingual complex verbs with yap- than monolingual speakers of Turkish or returnees. The younger returnees were expected to be on their way towards developing patterns that are similar to those of monolingual Turks, that is to show a) a lower frequency of [N-yap] and a higher frequency of [N-et] collocations and b) to use fewer bilingual complex verbs involving yap-. The older returnees who had been back for seven years upon recording were expected to no longer be significantly different from their monolingual peers.

\section{Methods}




\section{Informants}

The participants in the current study $(n=179)$ belong to three main groups, namely HSs in Germany $(n=45)$, returnees $(n=65)$ and a monolingual Turkish control group $(n=69)$. In each group, there is a subgroup of secondary school students (ages 14-16), and a subgroup of university students (ages 20-21). The secondary school students among the HSs will be referred to as the HS1 group and the university students as the HS2 group. The HSs were born in Germany and had always lived there, whilst the returnee group lived in Germany until the ages of 13 to 15 , after which they left for Turkey and continued their education there. From now on we will call the secondary school returnees the RT1 group and the university student returnees the RT2 group. The former were recorded approximately one year after return, whilst the latter took part around seven years after arrival. Finally the monolingual secondary school control group will be called the ML1 and their university counterparts the ML2 group.

The socio-economic background of the students was checked with the help of a questionnaire. The majority came from working class or lower middle class backgrounds. In order to avoid a social bias in comparing the results of the bilingual and the monolingual pupils, we excluded any students whose parents had had higher education from the monolingual control groups. For further details on the informants' background see Table 1 and Daller, Treffers-Daller and Furman (2011). As we have shown in previous work on the basis of analyses of the lexical richness of the stories and results of C-tests ${ }^{\mathrm{vi}}$ in both languages (Daller, Treffers-Daller \& Van Hout, 2003), the HSs are clearly dominant in German whilst the returnees are dominant in Turkish. The HSs used Turkish and German on a daily basis, but for different purposes. They used Turkish in the family, and with personal friends with the same backgrounds, but German in public domains, including in schools. Importantly, support for Turkish in schools was minimal. We know from questionnaire 
results reported in Daller $(1999,2005)$ that the returnees still used German with siblings, but in public domains they used Turkish only at the time of recording, except for some lessons at school or university.

[Insert Table 1 about here]

Instruments

The instrument used in this study was a story telling task. The so-called Father-and-son stories (Plauen, 1996 [1952]) were used to elicit narratives from each participant individually. The Turkish stories used in this project were a story in which the father and the son play football and the ball disappears in a manhole ("the ball story"), see the appendix of Daller et al. (2011) and a story in which a wasp stings the father during a meal ("the wasp story"). These two stories were told in Turkish by all informants ${ }^{\mathrm{vii}}$. The HS1 and RT1 groups also told a third story ("the homework story"), in which the father helps the son to do his homework and receives a punishment from his teacher. The homework story was used for the analysis of two variants of a specific noun-verb collocation (ders yap- "do a lesson" and ders çalış- "to study for a lesson), which occurred with sufficient frequency in this story to allow for a quantitative analysis.

\section{Procedure}

The data collection was carried out in the schools or universities of the participants by monolingual research assistants for the monolingual groups and by bilingual assistants for the bilingual groups. The participants were asked individually to tell two short picture stories aloud. In order to avoid translation effects, the bilingual participants were asked to tell different stories in German and Turkish. The German stories were not used for the current analysis. After completion of the story telling tasks, the research assistants collected 
information from students regarding their migration history and personal details using a questionnaire. Transcriptions were done by the research assistants (see Daller et al., 2011, for further details).

Data analysis

For each informant, we counted first of all how often they used yap- and et-, irrespective of the constructions in which they occurred in the two stories ${ }^{\text {viii }}$ and then we counted the occurrence of noun-verb collocations in the data of each informant. We subsequently converted these raw frequencies to relative frequencies, by computing how frequently these occurred as percentage of the total number of words used by each informant. Because the variables were not normally distributed we used non-parametric tests (the Kruskal Wallis and the Jonckheere-Terpstra tests) to analyse the data ${ }^{\mathrm{ix}}$. The Jonckheere-Terpstra test is similar to the Kruskal Wallis test but makes it possible to determine whether the groups we are comparing produce a meaningful order of medians (Field, 2013, p. 246), which is particularly useful in the current study where six groups are compared.

Finally we counted the frequency of occurrence of two variants of one specific verb-noun collocation (ders çalış- "study for a lesson" and ders yap- "do a lesson") in the third story as told by the HS1 and RT1 groups. For the intergroup comparison of the distribution of these data we used a Chi Square ${ }^{\mathrm{x}}$.

To reduce the risk of a type I error (i.e a rejection of the null hypothesis when it should not have been rejected), we report p-values adjusted for the number of tests, as provided in the output of the Jonckheere-Terpstra test. Effect sizes are reported for all intergroup differences (for the ways in which this is done with the Jonckheere test, see Field, 2013, p. 248). 


\section{Results}

Overall usage of yap and et-

We begin with an overview of overall usage of yap- and et- across all constructions, as this shows most clearly in which proportion both forms are used in each group. This includes constructions where yap- is used as a proform to replace verbs that were used before in the discourse (see Doğruöz \& Backus, 2009).Then we turn to the noun-verb collocations, and the bilingual complex verbs and finally we focus on the analysis of ders çalış- "study for a lesson" and ders yap- “do a lesson”.

The overall differences between yap- usage among all six groups were found to be significant $(H(5)=13.77, p=.017, r=.19)$ and the same was true for et- $(H(5)=50.77, p$ $<.001, \mathrm{r}=.26)^{\mathrm{xi}}$. Jonckheere's test revealed a significant trend in the data for yap- $(\mathrm{J}(5)=$ $7300.0, \mathrm{z}=2.13, \mathrm{p}=.033, \mathrm{r}=.16)$ as well as for et- $(\mathrm{J}(5)=8568.5, \mathrm{z}=6.20, \mathrm{p}<.001, \mathrm{r}=.47)$. The overall differences between the groups are given in Figure 2. This Figure shows that the older monolinguals and the older returnees are the most prolific users of et-, whilst the other groups use far more yap- than et-. Interestingly, the only group whose usage of et- appears to EXCEED their use of yap- are the older returnees (RT2), whilst among the pupil groups it is also the returnees (RT1) which appear to use et- more frequently than their peers of the same age (although the differences between the pupil groups are not significant - see below).

A more detailed picture of the differences between the six groups, as relevant for the current project, was obtained by carrying out the posthoc pairwise comparisons that are available under the Jonckheere-Terpstra test. With respect to yap-, the HS1 group was found to be significantly different from the ML1 group $(\mathrm{J}(1)=792, \mathrm{z}=2.770, \mathrm{p}=.042, \mathrm{r}=.33)$ and also from the HS2 group $(\mathrm{J}(1)=340, \mathrm{z}=2.78, \mathrm{p}=.041, \mathrm{r}=.41)$, but the returnee groups were not 
significantly different from the other groups. The HS1 group used, for example, an [N-yap] construction as in (10), and a mixed verbal compound ${ }^{\mathrm{xii}}$ as in (11). Further examples of the constructions can be found in Tables 2 and 3.

(10) Oğl-u da okul-da şımarık-lık falan şey-ler yap-mış

Son-POSS also school-LOC naughti-ness INT thing-PL do-EV/PF

"His son also did some naughty things, you know, in school." (OEZ, HS1)

(11) Top-u ç1k-ar-ken kafa-sı-nı tuşe yap-lyor (FER, HS1)

Ball-POSS leave-AOR-CV head-POSS-ACC touch do-PROG- $\varnothing$

"When the ball left (the manhole), he touched his head."

In their use of et- the HS1 group was significantly different from the HS2 group (J $(1)=$ $315.5, \mathrm{z}=2.83, \mathrm{p}=.035, \mathrm{r}=.42)$, as well as from the RT2 group $(\mathrm{J}(1)=788.5, \mathrm{z}=4.41, \mathrm{p}<$ $.001, \mathrm{r}=.55)$ and from the ML2 group $(\mathrm{J}(1)=661.5, \mathrm{z}=4.72, \mathrm{p}<.001, \mathrm{r}=.63)$.

The HS1 group uses only one [N-et] construction, shown in (12), and one mixed verbal compound with et-, which is given in (13).

(12) Oğl-u da cam-dan dışarı tut-ma-sı ikaz ed-er son-POSS also window-ABL outside hold-ANom-POSS warn do-AOR

"His son also warns him to hold it (the plate) outside the window." (CAN, HS1)

(13) Oğlan ağl-1yor, baba-s1 bağır-1yor, o zaman şey 
Boy cry-PROG- $\varnothing$, father-POSS scream-PROG- $\varnothing$, that time INT

versöhnen ed-iyor-lar (CIH, HS1)

reconcile do-PROG-PL

"The boy is crying, his father is screaming, then they reconcile."

The RT1 group was not significantly different from the HS1 group or the ML1 group, but the differences between the younger (RT1) and the older returnee groups (RT2) were significant $(\mathrm{J}(1)=715.0, \mathrm{z}=2.7, \mathrm{p}=.049, \mathrm{r}=.34)$. In addition, the $\mathrm{RT} 1$ group produced significantly fewer occurrences of et- than the ML2 $\operatorname{group}(\mathrm{J}(1)=610, \mathrm{z}=3.19, \mathrm{p}=.01, \mathrm{r}=.42)$. The RT2 group was significantly different from the ML1 group $(\mathrm{J}(1)=1076, \mathrm{z}=4.82, \mathrm{p}<.001, \mathrm{r}=$ $.58)$, but not from the ML2 group. Finally the two monolingual groups were significantly different from each other $(\mathrm{J}(1)=906, \mathrm{z}=5.19, \mathrm{p}<.001, \mathrm{r}=.65)$.

[Insert Figure 2 about here]

Noun-verb collocations

Next we turn to the results obtained from the analysis of the [N-yap] and [N-et] collocations. These results are shown in Figure 3. In Figure 3 the y-axis represents the number of [N-et] constructions per 100 words.

[Insert Figure 3 about here]

An analysis of [N-et] collocations with the Kruskal Wallis test revealed there were significant differences between the six groups in their use of [N-et] $(H(5)=48.47, p<.001, r$ $=.26)^{\mathrm{xiii}}$. In addition, Jonckheere's test revealed a significant trend in the data $(\mathrm{J}=8509.5, \mathrm{z}$ 
$=6.119, \mathrm{p}<.001, \mathrm{r}=.46)$. The results of the test are presented in graphic form in Figure 3, which clearly demonstrates there is an increase in the use of [N-et] from those with least contact to Turkish as spoken in Turkey (the youngest heritage speaker group HS1) to those with most contact with Turkish as spoken in Turkey (the older monolingual group ML2), whilst the returnees are in between these two groups. Only the younger returnee group (RT1) stands out as different in that this group uses more [N-et] constructions than would be expected for their age group (given the scores of the other pupil groups). This exceptional result will be discussed in section 4 in more detail. Pairwise comparisons with the Jonckheere-Terpstra test revealed that the HS1 group was significantly different from the RT2 $\operatorname{group}(\mathrm{J}(1)=773, \mathrm{z}=4.23, \mathrm{p}<.001, \mathrm{r}=.53)$ as well as from the ML2 group $(\mathrm{J}(1)=661.5$, $\mathrm{z}=4.72, \mathrm{p}<.001, \mathrm{r}=.63)^{\mathrm{xiv}}$. The two monolingual groups were also significantly different from each other $(\mathrm{J}(1)=1054.5, \mathrm{z}=4.61, \mathrm{p}<.001, \mathrm{r}=.38)$, which was unexpected (see discussion section) The younger returnee group (RT1) was significantly different from the ML2 group $(\mathrm{J}(1)=613, \mathrm{z}=3.26, \mathrm{p}=.008, \mathrm{r}=.43)$, but the older returnee group (RT2) was not significantly different from the ML2 group.

Further details about the types and the tokens of the [N-et] and the [N-yap] collocations can be found in Tables 2 and 3 which present the collocations found in the data from all groups. These tables show that it is not only the total number of tokens that changes, but also the number of types: the younger returnee group (RT1) avoids [N-yap] altogether, and produces only [N-et] collocations. One student in the HS1 group uses a German verb in this construction as illustrated earlier in (13). There is some evidence still of [N-yap] among the RT2 group, as can be seen in (14), where the German verb stechen "to sting" is inserted into the Turkish frame with yap-. 


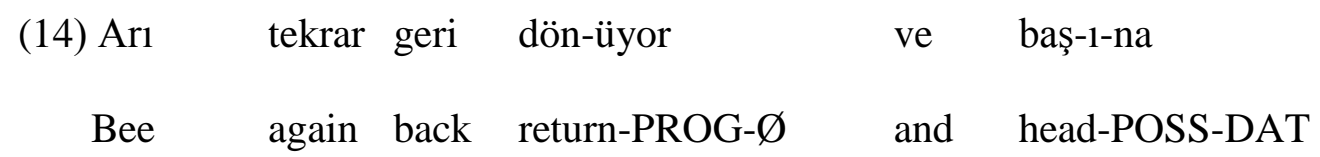

baş-1-nı sok-uyor, stechen yap-lyor yani (CUN, RT2)

head-POSS-ACC sting-PROG- $\varnothing \quad$ sting $\quad$ do-PROG- $\varnothing$ you know

"The bee returns and stings his head, his head, he stings it, you know."

The low number of such bilingual complex verbs is probably due to the fact that the informants were asked to speak Turkish in this task, which will have had an impact on their propensity to mix languages in the stories. This very small sample of complex verbs does however illustrate that there is some variability, because both yap- and et- are used to create bilingual complex verbs.

[Insert Table 2 about here]

It is also of interest to note that there are two uses of [N-et] collocations that appear to be unusual, with respect to the norms of Turkish as spoken in Germany, as well as those in Turkey. One member of the RT1 group uses maç et- "do a match" (as in 15), where in both varieties maç yap- would have been the preferred choice. The latter is indeed used both by a member of the RT2 group (16) and the ML2 group (17).

$\begin{array}{lll}\text { (15) Şimdi } & \text { baba-s1-yla } & \text { oğlan maç edi-yor } \\ \text { Now } & \text { father-POSS-with } & \text { son match do-PROG- } \varnothing\end{array}$

"Now the son plays a match with his father." (SER, RT1) 
$\begin{array}{rlrr}\text { (16) Birinci } & \text { resim-de baba-yla oğul maç yap-lyor-lar } \\ \text { First } & \text { drawing-LOC father-with son match do-PROG-PL }\end{array}$

san-1r-1m

believe-AOR-1st

"On the first drawing, the father and the son play a match.” (ARZ, RT2)

(17) Bun-lar mendi ara-lar-1n-da yap-lyor-lar

This-PL self interval-PL-POSS-LOC match do-PROG-PL

“They play a match among themselves." (AHM, ML2)

Another member of the RT1 group uses pas et- "do a pass" when talking about the football game between the father and the son. The more common expression would be pas at- "throw a pass" or pas ver- "give a pass". The fact that these younger returnees choose et- instead of the more common alternatives is possibly an indication of hypercorrect usages, which warrants further discussion in section 5.

[Insert Table 3 about here]

The data also reveal that some nouns can be used with et- as well as yap- (e.g. hareket yap"to make a movement" and hareket et- "to move"), both of which are found in the data. While the translation suggests they are very similar in meaning they cannot be used interchangeably. A detailed analysis of the qualitative differences in the use of et- and yap- in these constructions is beyond the scope of the current investigation, but we can provide an analysis of the variation in some noun-verb collocations in which the verb is variably 
replaced with the dummy verb yap-. This is the case with ders çalış- "study for a lesson" and ders yap- "do a lesson", of which the former is the more common one in Turkish as spoken in Turkey. This collocation occurs in the homework story, which was told only by the HS1 and the RT1 groups (see also the methods section). Looking at the options used by these two groups can give us an additional perspective on the changes that occur when Turkish HSs suddenly find themselves in an environment where a new variety of Turkish is spoken. Figure 4 shows that ders yap- is used more often by the HS1 group, but ders çallş- is clearly more popular with the RT1 group and this difference is significant $\left(\mathrm{X}^{2}(1)=4.99, \mathrm{p}=.025\right)^{\mathrm{xv}}$. As we do not have a monolingual control group which carried out this task, we also verified whether ders collocates more strongly with çalış or with yap- in Turkish as spoken in Turkey by searching the web-based sketchengine corpus (3.370 million words, collected between December 2011 and January 2012 ${ }^{\mathrm{xvi}}$ ). We found that the association between ders and çallşwas much stronger than that between ders and yap-. ${ }^{\text {xvii }}$

[Insert Figure 4 about here]

To summarize, we can conclude that there are important differences between the groups in their use of noun-verb collocations in that the younger returnee group (RT1) avoids [N-yap] collocations altogether, and prefers [N-et], whilst the younger heritage speakers (HS1) used significantly fewer [N-et] than the RT2 group and the ML2 group. The differences between the HS1 and the RT1 groups were not statistically significant with respect to their use of [N-et], possibly because the RT1 group is only 1.7 years older than the HS1 group and not enough time has elapsed to develop knowledge of [N-et] collocations. However, the HS1 group made significantly more use of the light verb yap- in the 
collocation ders yap- "to do a lesson", whilst the RT1 group preferred ders çalış "to study for a lesson", which is the variant preferred in standard Turkish. The last point illustrates that some of the differences between the groups are of a purely quantitative nature: the different constructions are found in all groups but in used in different frequencies. In fact, in some cases, the same speaker uses both forms, as was also the case with the bilingual complex verbs found among Turkish-German bilingual informants in Kallmeyer and Keim's (2003) data (see example 9). Changes in frequency of usage of one variant over another (e.g. ders çalış instead of ders yap-) reflect quantitative convergence towards the norm that is prevalent in Turkey rather than qualitative differences in meaning or use.

There were a few qualitative differences, however, between both groups with respect to the diversity of [N-et] collocations, of which the RT1 group used a wider range than the HS1 group, including a few rather unusual ones. As might have been expected, the diversity of [Net] collocations was much smaller among the older heritage speakers (HS2) than among the RT2 and the ML2 groups. The older returnee group (RT2) was not significantly different from the older monolingual group (ML2) in their use of either of [N-et] or [N-yap], which shows that the older returnee group has successfully converged towards the conventions of Turkish as spoken in Turkish.

\section{Discussion and conclusion}

This study confirms findings of Doğruöz and Backus (2009) and Pfaff (2000) that HSs prefer yap- over et- across a range of constructions, and that yap- is the conventional choice in collocations among HSs. The current study has added to our existing knowledge by comparing HSs' use of these forms to that of returnees, which provides a new perspective on 
the ability of HSs to learn new conventional expressions, even after the age of twelve. It is remarkable that the younger returnee group (RT1) makes such extensive use of et-, and completely avoids verb collocations with yap-. Although the RT1 group had only been back in Turkey for one year, they clearly learned that et- is the more common verb in collocations in their new environment, and that yap- as a light verb in ders yap- "to do a lesson" is not the preferred variant in Turkey. The fact that there is a significant difference between the HS1 group and the RT1 group in the choice of this noun-verb collocation (although the latter are only 1.7 years older than the former), supports the view that the RT1 group is already on its way to adapt to the Turkish norms they have been immersed in since return. The RT1's use of maç et- and pas et- which is unusual in Turkish, supports the assumption that these returnees are overusing et-: the choice of et- in maç et- and pas et- is in fact hypercorrect. It is likely that the use of yap- carries a stigma and is seen as characteristic of almancllar, that is Turks who are recognisable as coming from Germany, and that the new returnees are particularly sensitive to this stigma. Some evidence for the fact that Turkish-German speakers are sensitive to subtle differences in the use of these verbs can be obtained from Pfaff (2000) who noticed that small Turkish children in Berlin conform to the diaspora variety of their peers by increasingly using yap- instead of et- to form noun-verb collocations. Upon return to Turkey, our informants experience the same kind of pressure, but in the opposite direction. ${ }^{\text {xiii }}$ This also provides indirect evidence for the source of difference between HSs and monolinguals related to whether the HSs' performance stems from true incomplete acquisition or is more a reflection of qualitative differences in their input for this domain. Since members of the RT1 group who would have reasonably been classified as HS1 type learners a year prior make pervasive changes to their et-usage in such short order, it is reasonable to conclude that correlation of this change can be likened to the isolated variable that differentiates the HS and RT groups in the first place; that is, to difference in input exposure to a (new) variety that 
provides sufficient input for it. These data seem to suggest that the term incomplete acquisition is not correct at all to refer to Turkish-German HSs, but that their language profiles are rather explained by the tenets of the Missing Input Competence (MIC) hypothesis (Rothman, 2007; Pires \& Rothman, 2009)

In this context it is important to note that the younger and the older monolinguals differ so strongly from each other in their use of et- too. It is the older monolinguals who use et- most frequently, which could indicate that some of the expressions in which et- is used belong to a register that is acquired later in life. In other words, the use of et- could be agegraded. The fact that et- is used to integrate Arabic, French, Iranian and other loan words into Turkish (Backus, Aarssen \& van der Heyden, 2006) indicates that this is a plausible explanation. However, one cannot ignore the fact that the RT1 and RT2 groups also differ in amount of exposure confounded with length of exposure to Turkish in Turkey. A plausible explanation for the differences between these two groups can thus be a developmental one. In other words, the differences between the two RT groups may not related to age of exposure to Turkish in Turkey at all, but could rather reflect unique stages in development. What the data clearly reveal is that one year of exposure to Turkish in Turkey is sufficient for them to recognize the preference for et- and the marked nature of yap-. Yet the journey to acquire the conventional patterns takes longer than one year, whereby the RT2 group reflects a point of ultimate attainment and the RT1 group reflects a grammar that has not reached ultimate attainment yet.

If our interpretation is correct that the returnees have acquired these collocations since return, this has important implications for theories of language acquisition. It shows that HSs can acquire new collocations after the onset of puberty and that after a certain time has elapsed they are no longer significantly different from monolingual users of Turkish once they find themselves in monolingual environments of the heritage language. This was also the 
conclusion we reached in our study of syntactic embeddings (Treffers-Daller, et al., 2007), and our study of motion event cognition (Daller et al., 2011). This does not mean that heritage grammars are "fixed" by exposure to more monolingual input over time, as we do not take heritage speaker grammars to be broken in the first place. The idea is not that monolingual exposure completes a heritage grammar that was incomplete. In fact, the heritage grammars are complete for the norms of the heritage community, which simply differ in non-evaluative ways from monolingual ones. As discussed above, the fact that after only one year of exposure to an abundance of monolingual normative use the returnee group was able to switch preference towards that norm indicates that HSs, even as young adults, remain very sensitive to the input of their new environment. If they remain sensitive even in adulthood, then one must assume they are at least as sensitive to input in the environment as children. Thus, one who would label the performance of our HS groups as incomplete faces a difficult problem of explanation. The returnees are different from the late L2 learners in Foster (2009a,b), who started learning English after the age of twelve or advanced learners in, for example, Wang and Shaw (2008) who were unable to produce or recognise lexical patterns to the same level as monolinguals. This is perhaps not too surprising since in the case of HSs who become returnees the learning task is unique compared to L2ers. L2ers start the learning of a second language in adulthood needing to acquire the relevant lexical items as well as their collocational patterns (and much more), whereas returnees need only reassemble in adulthood their preferences for collocations of units that were acquired in childhood. In this sense, only the L2ers approach the learning of Turkish with no previous language-specific experience. Lexis acquisition continues throughout the lifespan even in an L1, so the claim by Foster is not that the issue is a problem with L2 lexical acquisition but rather is one related to an inability to recognize and use patterns, an ability that is hypothesized to be lost because of age-related maturation. However, since the returnees are 
also adults and since just like the case of L2 learners their task requires pattern recognition it should follow from Foster's claims that they too would have similar problems. This is clearly not the case, however. Our data show that the pattern is recognized early and even eventually the returnee groups adjust to conventional usage as found among monolinguals in the country of origin. And so, we submit that it cannot be age alone that determines whether or not a particular pattern can be recognized and incorporated, but rather that it must be something else that conspires in the case of L2ers to explain results of the type Foster offers. The problem for L2ers might have more to do with any number of other differences that exist between them and the returnees, but crucially not the shared variable of age alone.

From the above discussion, we also see how returnees as a group provide important insight to theoretical debates in related literatures. Returnees of an adult age provide a unique comparison group for adult L2ers and can provide some crucial evidence related to age-ofexposure debates; anything argued to not be possible for adult L2ers as a function of increased age should also apply to adult returnees. Claiming that the cause of L2er performances as in Foster (2009a,b) is an inability to recognize patterns caused/conditioned by age is refuted on the basis of our returnee data precisely because the crucial variable assumed to explain the L1 versus L2 differences is shared and held constant across typical adult L2ers and our adult returnees, yet the latter show no differences to the L1ers. To be clear, it is not our position that returnees can do something that L2ers a priori cannot as Ding's (2007) evidence about L2 learners' ability to learn formulaic sequences demonstrates.

We are aware that HSs in bilingual contexts do receive input from monolinguals as well as from bilinguals, so why does it take being in the monolingual environment for a sustained period of time to see shifts like the ones we have noted in the data? We would contend that it is likely the environment itself. There is considerable evidence that returnees experience strong pressure to assimilate to Turkish culture after return (Brach, 2012; Daller, 
2005; Sackmann et al., 2005 \& Schneider, 2009) and learning a new variety of Turkish is an integral part of this. It is reasonable to assume a priori that the social situation of returnees is thus different from that of typical L2 learners who do not experience such intense pressure to assimilate to target language cultural and linguistic norms, precisely because returnees are native, albeit bilingual speakers of the environmental language (cf. Rothman \& TreffersDaller, 2014). Returnees go back to Turkey, where they enter the school system and are exposed to not only the standard but also a process of becoming increasingly more literate in the standard variety (see Rothman, 2007; Pires \& Rothman, 2009). Our conclusion is not that the returnees have filled in the gaps in their Turkish knowledge, but that in short order they have acquired the standard dialect of Turkish as now increasingly educated and literate speakers thereof and this process gives rise to emerging knowledge that by comparison to HSs is different.

We are mindful of the limitations inherent to the oral production data we have analysed. We cannot make any claims about the returnees' or HSs' ability to process of these collocations nor can we speak about their ability to comprehend nuances in related interpretation. Future studies of returnees will need to focus on these areas. We submit that returnees are a crucial group that can provide important new insights not only into the specific characteristics of language knowledge and use among HSs and by comparison to other adult learner groups such as L2ers, but also for the wider theory of how languages are acquired, how they vary, and how they change. 


\section{References}

Aarssen,J., Backus, A. \& Van der Heijden, H. (2006). Turkish in the Netherlands. In H. Boeschoten, \& L. Johanson (eds.). Turkic languages in contact, pp. 220-240. Wiesbaden: Otto Harrassowitz.

Altenberg, B., \& Granger, S. (2001). The grammatical and lexical patterning of MAKE in native and non-native student writing. Applied Linguistics, 22, 173- 195.

Backus, A. (1996). Two in one. Bilingual speech of Turkish immigrants in the Netherlands. Tilburg: Tilburg University Press.

Backus, A., \& Boumans, L. (1996). Codewisseling en taalvariatie bij Turkse en Marokkaanse jongeren. In H. Heeren, P. Vogel, \& H. Werdmolder (eds.), Etnische minderheden en wetenschappelijk onderzoek. Veranderingen in taal, recht, religie en sociaaleconomische positie in Nederland, pp. 141-163. Amsterdam/Meppel: Boom.

Brach, L. (2012). Almancılar go Turkey. Rückkehr in die "Heimat" oder Transmigration. Hamburg: Diplomica Verlag.

Benmamoun, Montrul and Polinsky (2013). Defining an "ideal" heritage speaker: theoretical and methodological challenges. Reply to peer commentaries. Theoretical linguistics. In press.

Boeschoten, H. E. (1990). Acquisition of Turkish by Immigrant Children: A Multiple Case Study of Turkish Children in the Netherlands Aged 4 to 6. Wiesbaden: Harrassowitz. Boeschoten, H. (1998). The speakers of Turkic languages. In L. Johanson \& E. A. Csato (eds.), The Turkic languages, pp. 1-15. New York: Routledge.

Daller, H. (1995). The academic language proficiency of Turkish returnees from Germany. Language, Culture and Curriculum, 8, 163-174.

Daller, H. (2005). Migration und bilinguale Sprachentwicklung: Türkische Rückkehrer aus Deutschland. In V. Hinnenkamp \& K. Meng (Eds.). Sprachgrenzen überspringen: 
Sprachliche Hybridität und polykulturelles Selbstverständnis (pp. 325-344). Tübingen: Gunter Narr.

Daller, H. \& Grotjahn, R. (1999). The language proficiency of turkish returnees from Germany: an empirical investigation of academic and everyday language proficiency. Language, Culture and Curriculum, 12, 165-172.

Daller, M. H. \& Treffers-Daller, J. (2014). Moving between languages: Turkish returnees from Germany. In B.Menzel \& C. Engel (Eds.). Rückkehr in die Fremde? Etnische Remigration russlanddeutscher Spätaussiedler (pp. 185-212) Berlin: Frank \& Timme GmbH.

Daller, H., Treffers-Daller, J., Ünaldi-Ceylan, A. \& Yildiz, C. (2003). The development of a Turkish C-Test. In J. Coleman, R. Grotjahn \& U. Raatz (Eds.), University Language Testing and the C-Test (pp. 187-199). AKS-Verlag Bochum.

Daller, M., Treffers-Daller, J. \& Furman, R. (2011). Transfer of conceptualisation patterns in bilinguals: the construal of motion events in Turkish and German. Bilingualism, Language and Cognition, 14, 95-119.

Ding, Y. (2007). Text memorization and imitation: The practices of successful

Chinese learners of English. System, 35, 271-280.

Dirim, İ. \& Auer, P. (2004). Türkisch sprechen nicht nur die Türken. Berlin: Walter de Gruyter.

Doğruöz, A.S., \& Backus, A. (2009). Innovative constructions in Dutch Turkish: An assessment of on-going contact-induces change. Bilingualism: Language and Cognition, 12, 41-64.

Durrant, P. \& Schmitt, N. (2010). Adult learners' retention of collocations from exposure. Second Language Research, 26, 163-188.

Ellis, R. (2002). Reflections on frequency effects in language processing. Studies in Second Language Acquisition, 24, 297-339. 
Field, A. (2013). Discovering statistics using IBM SPSS statistics (4 ${ }^{\text {th }}$ ed.). Los Angeles: Sage.

Flores, C. (2010). The effect of age on language attrition: Evidence from bilingual returnees. Bilingualism: Language and Cognition, 13, 533-546.

Foster (2009a). Lexical diversity and native-like selection: The bonus of studying abroad. In B. Richards, B., M.H. Daller, D.D. Malvern, P. Meara, J. Milton \& J. Treffers-Daller (eds.), Vocabulary studies in first and second language acquisition, pp. 91-106. Houndmills: Palgrave MacMillan.

Foster, Pauline (2009b). Native-like selection in second language acquisition: the effects of age, aptitude and socialisation. ESRC End of Award Report, RES-000-22-2645. Swindon: ESRC.

Fritsche, M. (1982). Mehrsprachigkeit in Gastarbeiterfamilien. "Deutsch" auf der Basis der türkischen Syntax. In K.H. Bausch (ed.), Mehrsprachigkeit in der Stadtregion, Sprache der Gegenwart 56, Jahrbuch 1981 des Instituts für deutsche Sprache, pp. 160-170. Düsseldorf: Schwann.

German Ministry of Education (2006). Konzepte für den bilingualen Unterricht Erfahrungsbericht und Vorschläge zur Weiterentwicklung. Sekretariat der ständigen Konferenz der Kultusminister der Länder in der Bundesrepublik Deutschland.

Göksel, A. \& Kerslake, C. (2005). Turkish: A Comprehensive Grammar. London \& New York: Routledge.

Jespersen O. (1954). A Modern English Grammar on Historical Principles. London: George Allen \& Unwin and Copenhagen: Ejnar Munksgaard.

Johanson, L. \& Csato, E.A. (1998) (eds.). The Turkic languages. Routledge. Language Family Descriptions. London: Routledge. 
Kallmeyer,W. \& Keim, I. (2003). Linguistic variation and the construction of social identity in a German-Turkish setting: A case study of an immigrant youth group in Mannheim, Germany. In J.K. Androutsopoulos \& A. Georgakopoulou (eds.), Discourse constructions of youth identities, pp. 29-46. Amsterdam: John Benjamins.

Klein-Braley, C. \& Raatz, E. (1984). A survey of research on the C test. Language Testing, 1, 134-146.

Kornfilt, J. (1997). Turkish. London and New York: Routledge.

Laufer, B. \& Waldman, T. (2011). Verb-Noun collocations in second language writing: A corpus analysis of learners' English. Language Learning, 61, 647-672.

Lennon, P. (1996). Getting 'easy' verbs wrong at the advanced level. IRAL: International Review of Applied Linguistics in Language Teaching, 34, 23-36.

MacWhinney, B. (2005). Emergentism: use often and with care. Applied Linguistics, 27, 729-740.

Montrul, S. (2008). Incomplete Acquisition in Bilingualism. Re-examining the Age Factor. Amsterdam: John Benjamins.

Montrul, S., \& Bowles, M. (2009). Back to basics: Differential Object Marking under incomplete acquisition in Spanish HSs. Bilingualism: Language and Cognition, 12, 363-383.

Muysken, P. (2000). Bilingual Speech. A typology of code-mixing. Cambridge: Cambridge University Press.

O'Grady, W. (2013). The illusion of language acquisition. Linguistic Approaches to Bilingualism, 3, 253-285.

Özbek, A. (2010). On Çek- as a light verb: A contrastive view from Japanese. Journal of Language and Linguistic Studies, 6,1-13. 
Pacual y Cabo, D. \& Rothman, J. (2012). The (il)logical problem of heritage speaker bilingualism and incomplete acquisition. Applied Linguistics, 33, 450-455.

Pawley, A., Syder, F.H. (1983). Two puzzles for linguistic theory: nativelike selection and nativelike fluency. In J.C. Richards \& R.W. Schmidt (eds.), Language and Communication, pp. 191-226. Longman, New York.

Pfaff, C. W. (1991). Turkish in contact with German: language maintenance and loss among immigrant children in West Berlin. International Journal of the Sociology of Language, 90, 97-129.

Pfaff, C. W. (2000). Development and use of et- and yap- by Turkish/German bilingual children. In A. Göksel \& C. Kerslake (eds.), Studies on Turkish and Turkic languages, pp.365-373. Wiesbaden: Otto Harrassowitz.

Pfaff, C.W. (2013). Sociolinguistic and Psycholinguistic Research on Heritage Language Speakers. Perspectives from studies of children and adolescents with Turkish background in Germany. Seventh Heritage Language Research Institute, Chicago, June 17-21, 2013.

Pires, A. \& Rothman, J. (2009). Disentangling sources of incomplete acquisition: An explanation for competence divergence across heritage grammars. International Journal of Bilingualism, 13, 211-238.

Plauen, E.O. 1996 [1952]). Vater und Sohn (Band 2). Ravensburger Taschenbuchverlag. Polinsky, M. (2011). Reanalysis in adult heritage language. New Evidence in Support of Attrition. Studies in Second Language Acquisition, 33, 305- 328.

Rehbein, J. (1987). Sprachloyalität in der Bundesrepublik? Ausländische Kinder zwischen Sprachverlust and zweisprachiger Erziehung. Universität Hamburg: Arbeiten zur Mehrsprachigkeit, 26. 
Rothman, J. (2007). Heritage speaker competence differences, language change and input type: Inflected infinitives in heritage Brazilian Portuguese. International Journal of Bilingualism, 11, 359-389.

Rothman, J. (2008). Why not all counter-evidence to the Critical Period Hypothesis is equal or problematic: Implications for SLA. Language and Linguistics Compass, 2, $1063-$ 1088.

Rothman, J. (2009). Understanding the nature and outcomes of early bilingualism: Romance languages as heritage languages. International Journal of Bilingualism, 13, 155-164.

Rothman, J. \& Treffers-Daller, J. (2014). A prolegomenon to the construct of the native speaker: Heritage speaker bilinguals are natives too! Applied Linguistics, 35, 93-98.

Rychlý, P. (2008). A lexicographer-friendly association score. In: P. Sojka \& a. Horák (Eds.) Proceedings of Recent Advances in Slavonic Natural Language Processing, RASLAN (pp. 6-9). Brno: Masaryk University.

Siegel, S. \& Castellan, N.J. jr. (1998). Non-parametric statistics for the behavioral sciences ( $2^{\text {nd }}$ ed.). New York: McGraw-Hill

Sackmann, R., Schultz, T., Prümm, K. and Peters, B. (2005). Kollektive Identitäten, Selbstverortungen türkischer MigrantInnen und ihrer Kinder. Frankfurt am Main: Peter Lang.

Schaufeli, A. (1991). Turkish in an immigrant setting. A comparative study of the first language of monolingual and bilingual Turkish children, Unpublished Dissertation, University of Amsterdam.

Schneider, J. (2009). From "Kanak Attack" to the "GerKish Generation": Second Generation Turkish Narratives in German Culture and Politics. In C. Inglis, S. Akgönül, \& S. De Tapia (eds.), Turks Abroad: Settlers, Citizens, Transnationals. International Journal on Multicultural Societies (IJMS), 11, 212- 229. 
Schwartz, B. D. \& Sprouse, R. A. (1996). L2 cognitive states and the Full Transfer/Full Access model. Second Language Research, 12, 40-72.

Slabakova, R. (2006). Is there a critical period for semantics? Second Language Research, $22,302-338$.

Treffers-Daller, J., Özsoy, A.S. \& van Hout, R. (2007). (In)complete acquisition of Turkish among Turkish-German bilinguals in Germany and Turkey: an analysis of complex embeddings in narratives. International Journal of Bilingualism and Bilingual Education, 10, 248-276.

Türker, E. (1993). Fremmedord bilmiyom" . A sociolinguistic study of second generation immigrant Turkish in Norway. Unpublished MA thesis: University of Oslo.

Türker, E. (2000). Turkish-Norwegian codeswitching. Evidence from intermediate and second generation Turkish immigrants in Norway. University of Oslo.

Uçar, A. (2010). Light verb constructions in Turkish dictionaries: are they submeanings of polysemous verbs? Dil ve edebiyat dergisi. Journal of Linguistics Literature, 7, 1-17.

Verhoeven, L.Th. and H. Boeschoten (1986), First language acquisition in a second language submersion environment. Applied Linguistics, 7, 241-256.

Wang, Y., \& Shaw, P. (2008). Transfer and universality: Collocation use in advanced Chinese and Swedish learner English. ICAME Journal, 32, 201-232.

White, L. (2003). Second language acquisition and Universal Grammar. Cambridge University Press.

Wray, A. (2002). Formulaic language and the lexicon. Cambridge: Cambridge University Press.

Wray, A. (2009). Future directions in formulaic language research. Journal of foreign languages, 32, 2-17. 
Notes

'As in our view native-like usage cannot be equated with monolingual usage (Rothman \& Treffers-Daller, 2014), which appears to be done in many studies, we prefer not to use the term "native-like", and use "conventional among monolingual users" instead.

ii As one reviewer points out, many fixed expressions are smaller than a clause, and consist of just a (part of a) phrase.

iii Doğruöz and Backus (2009) also discuss the use of yap- as a proform to replace verbs that were used before in the discourse, but including this usage was beyond the scope of the current paper.

iv The meaning of the abbreviations used in the glosses is as follows: $\mathrm{ABL}=$ ablative, $\mathrm{ACC}=$ accusative, $\mathrm{AOR}=$ aorist, $\mathrm{CV}=$ converb, $\mathrm{DAT}=$ dative, $\mathrm{EV} / \mathrm{PF}=$ evidential $/$ perfective , FUT=future tense, GerPL=German plural form, INT=interjection,LOC=locative, $\mathrm{NEG}=$ negative, $\mathrm{PAST}=$ past tense, $\mathrm{PL}=$ plural, $\mathrm{POSS}=$ possessive, $\mathrm{PROG}=$ progressive, $\mathrm{REL}=$ relative clause, $1 \mathrm{SG}=$ first person singular, $\varnothing=$ zero inflection.

${ }^{v}$ It is interesting that there is a dative case $-\mathrm{a}$ on yapanlar-a, because gratulieren assigns a dative case in German but the Turkish equivalent kutlamak "to congratulate" assigns accusative case to objects. Therefore it seems that the speaker uses the German case system in constructing the Turkish sentence, which is untypical as in most cases it is the Turkish case that is assigned in such examples.

${ }^{v i} \mathrm{~A}$ C-test is a variant of the Cloze test. The second half of every second word is deleted and needs to be restored by the test takers. The C-test principle was developed by Klein-Braley and Raatz (1984). 
vii The students were allowed to tell the stories in any order they wanted. Differences in the order in which they were told were not significant.

viii We excluded one informant from the RT2 group who used yap- nine times in the stories, whilst the maximum for others was six. He mainly used the expression şey yap- "to do a thing" as a filler when planning his utterances. As his behaviour was very different from that of the other informants, we decided not to use his data.

${ }^{\text {ix }}$ An anonymous reviewer commented on possible insufficient statistical power of the tests used in an earlier version of this article when we used $\chi^{2}$. We therefore reanalysed our data so that we obtained individual scores on the different variables for all informants. As the data were not normally distributed we used non-parametric tests that were suitable for ordinal data (the Kruskal-Wallis and the Jonckheere-Terpstra) in this version with a statistical power that comes close to that of parametric tests (for a discussion see Siegel \& Castellan, 1988, p. 215 and 222).

${ }^{\times}$We used raw frequencies because for a $\chi^{2}$ raw frequencies need to be used and not relative frequencies.

${ }^{x i}$ For details of the procedure for calculating effect size on Kruskal Wallis with more than 1 df, see Field (2013, p. 248). One has to bear in mind that this effect size summarises a general effect and intergroup comparisons with two groups might be larger. For the second Kruskal Wallis test the effect size is an estimate only because SPSS does not give more than three decimals of the p-value.

xii In this particular example the verb toucher "to touch" stems from French rather than German. See Boeschoten (1998) and Johansson (1998) for more details about the integration of foreign verbs into Turkish.

xiii For this Kruskal Wallis test the effect size is an estimate only because SPSS does not give more than three decimals of the p-value. 
${ }^{\text {xiv }}$ We report p-values adjusted for the number of tests, as provided in the output of the Jonckheere-Terpstra test.

xv The raw figures are as follows: HS1 37 ders yap-, and 2 ders çalış-. RT1: 15 ders yap- and 5 ders çalış-.

xvi As one reviewer points out, it would have been helpful to obtain some information about the genres represented and the age and educational background of the speakers/writers but this information is unfortunately not available on the sketchengine database.

xvii The strength of the collocation is computed with LogDice (Rychlý, 2008). The values have a theoretical maximum of 14, which means all occurrences of word A co-occur with word B and vice versa. The different inflected forms of çalış- and yap- make this comparison complex, but collocations of ders with the first six most frequent inflected forms of çalış have LogDice values between 7.685 and 6.446, whilst those for ders and yap- are between 5.302 and 4.875 .

xviii As one reviewer has pointed out, it is possible that this also applied to other conventional expressions, but there is no list of such expressions available for Turkish as spoken in Turkey, which makes it difficult to carry out such analyses. 


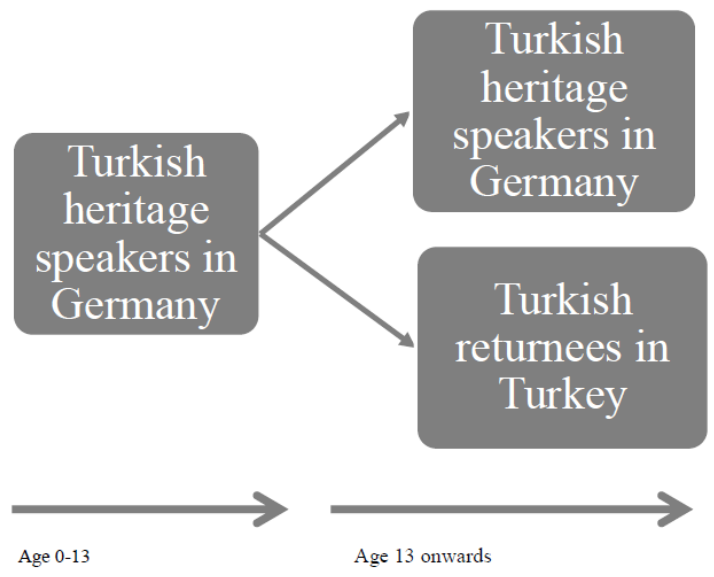

Fig. 1 Illustration of the relationship between the returnees and the heritage speakers

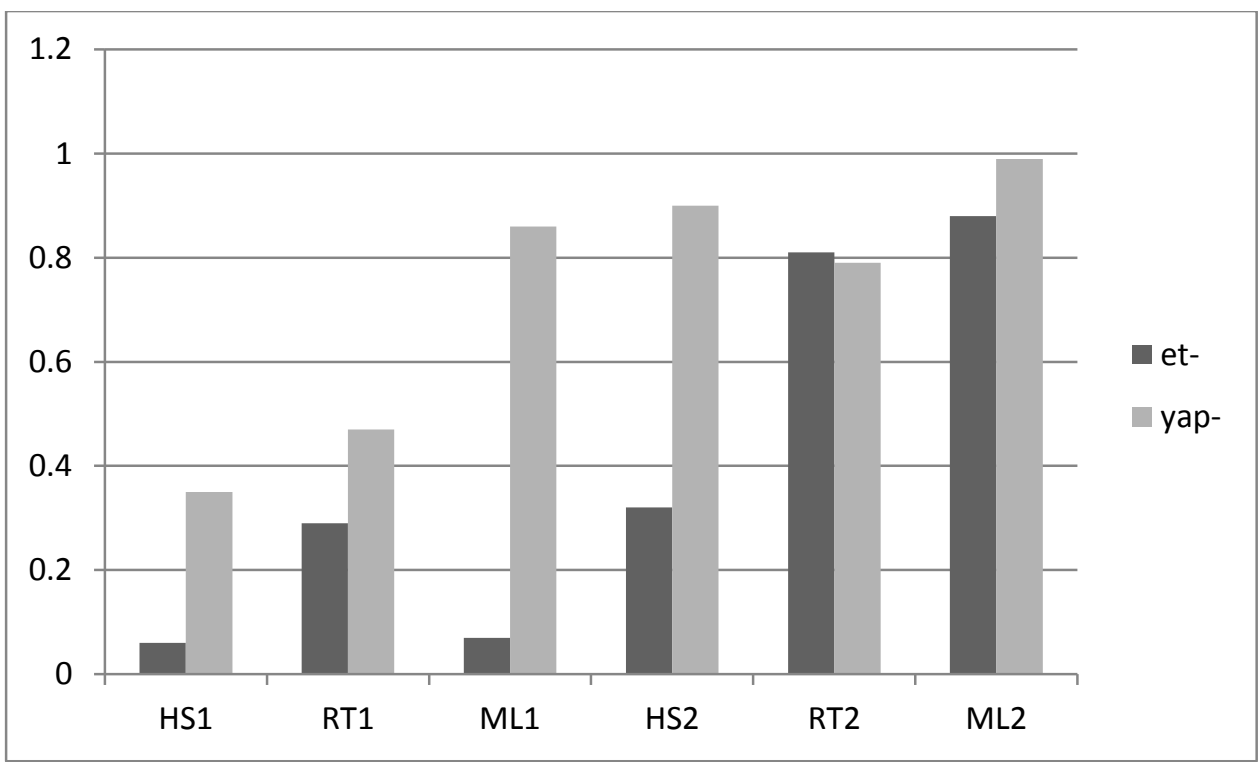

Figure 2. Relative frequency of yap- and et- across all groups and constructions 


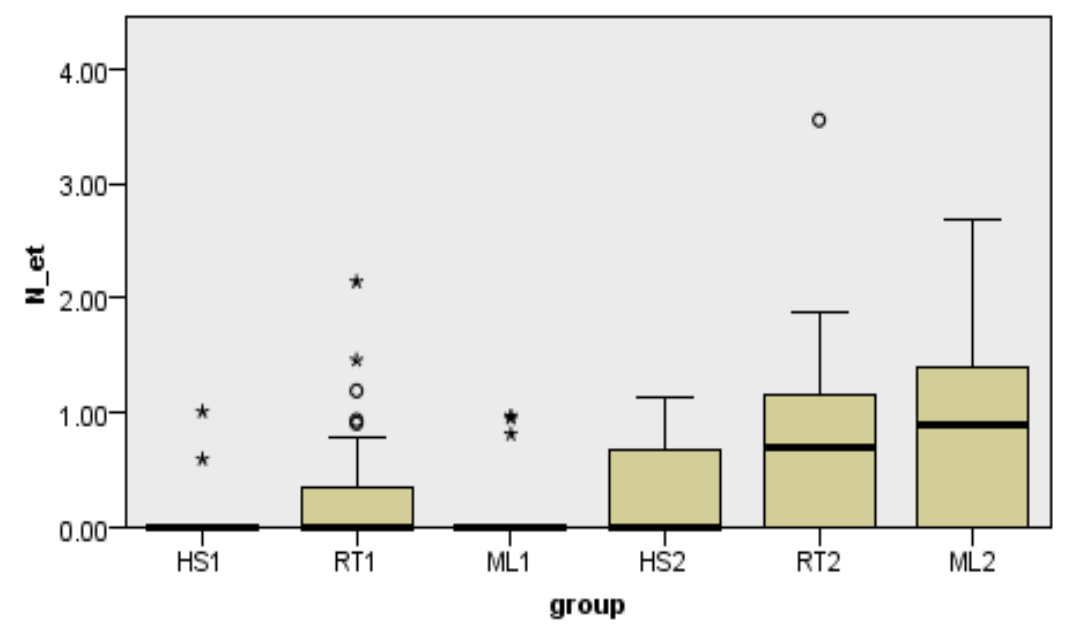

Figure 3. Relative frequency of noun-verb collocations with [N-et]

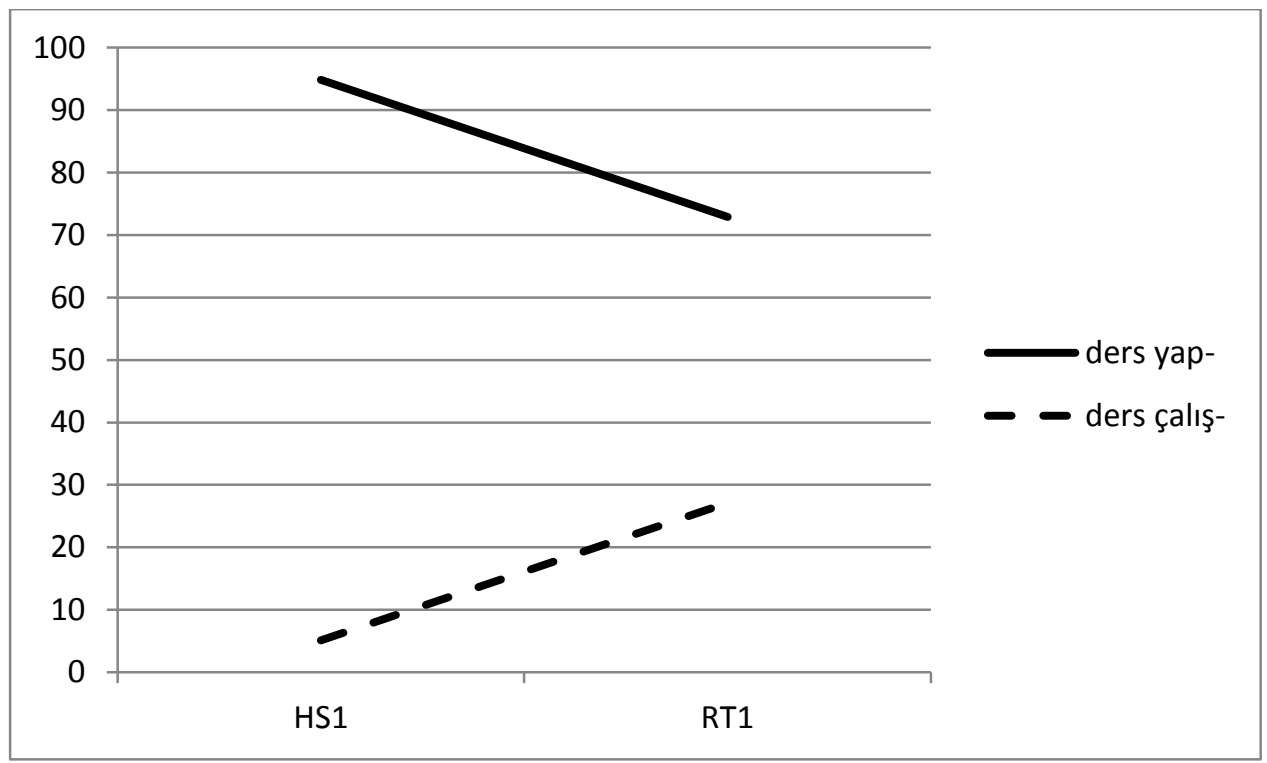

Figure 4. Frequency of ders yap- "do a lesson" and ders çalış- "study for a lesson" among the HS1 and RT1 groups 